\title{
The association of the IL-13-31 polymorphism and development of neuroinfections
}

\author{
Grażyna Biesiada' ${ }^{1,2}$, Jacek Czepiel ${ }^{1,2}$, Anna Piątek ${ }^{2}$, Malwina Birczyńska², Justyna Żuranska ${ }^{3}$, \\ Paweł Wołkow ${ }^{3}$, William Perucki ${ }^{4}$, Michał Jędrychowski ${ }^{2}$, Aleksander Garlicki ${ }^{1,2}$
}

${ }^{1}$ Department of Infectious and Tropical Diseases, Jagiellonian University, Medical College, Poland

${ }^{2}$ Department of Infectious Diseases, University Hospital in Cracow, Poland

${ }^{3}$ Center for Medical Genomics OMICRON, Jagiellonian University Medical College, Krakow, Poland

${ }^{4}$ Department of Medicine, John Dempsey Hospital, University of Connecticut, Farmington, CT, USA

\begin{abstract}
Introduction. Inflammation of the meninges can have various clinical courses, from mild, self-limiting in some viral neuroinfections to severe, sometimes ending in death. The pro-inflammatory cascade and defects in the inhibitors of the inflammatory response play an important prognostic role. Single nucleotide polymorphisms (SNPs) of the genes encoding cytokines, influence the severity of the inflammatory response.

Aim. The aim of this study was to evaluate the effect of selected polymorphisms of proinflammatory cytokines IL-1 $\beta$, TNF- $\alpha$ and IL-8 on the development of neuroinfections.

Material and Methods. We evaluated the laboratory results of 30 patients treated for bacterial and viral meningitis and compared those to 30 healthy volunteers. The following 4 variants were analyzed for occurrence of genetic polymorphism in patients with meningitis versus the control group: IL-1 33953 , IL-1 $\beta-31$, TNF- $\alpha-308$, and IL-8 781. Then, we assessed the association between these genetic polymorphisms and the inflammatory response during the course of meningitis.

Results and Conclusions. We observed that polymorphism of the IL-1 $\beta-31$ significantly differs between patients and healthy subjects, the IL-1 $\beta$-31AA polymorphism existed only in healthy individuals $(p<0.001)$. The WBC count was dependent on the TNF- $a-308$ polymorphism with a statistically significant difference $(p=0.021)$ occurring among persons with variants $A A$ and $A G$. In conclusion the study showed that the presence of the AA genotype of IL-1 $\beta$-31polymorphism may have a protective effect on the development of meningitis. This polymorphism was not observed in any patient with meningitis.
\end{abstract}

Keywords: polymorphisms of genes, neuroinfection, IL-1 $\beta$, TNF- $a$, IL-8.

\section{Introduction}

The pathophysiology of meningitis is a complex process which consists of factors dependent on the micro-organisms (eg. endotoxins, adhesive ability, the presence of the areola), and host factors [1, 2]. Proinflammatory cytokines, activated by bacterial or viral antigens, play a very important role in causing damage to the blood-brain barrier, and the result is the penetration of bacteria into the subarachnoid space and the development of the classic symptoms of the disease
$[3,4]$. Various courses of disease from mild to very severe in the case of the same causative pathogens have been observed, indicating that the proinflammatory pathway and defects in inhibitors of the inflammatory pathway play a very important predictive role. Single nucleotide polymorphisms (SNPs), genes that encode cytokines, influence the severity of the inflammatory response. Identifying these will allow an accurate assessment of the patient's prognosis. Classification of meningitis depends on the type of etiologic 
agent, there are two main groups: bacterial meningitis $(\mathrm{BM})$ and viral meningitis (VM) $[5,6]$. BM, due to the type of pathogens that cause inflammation are divided into purulent and non-purulent $[5,7]$. VM are usually mild, with a self-limited course and rarely cause neurological sequelae, and have a low mortality rate $[6,8$, 9]. However, there are cases of VM described with quite dramatic courses [5, 8-10].

Aim

The aim of our study was to evaluate the influence of

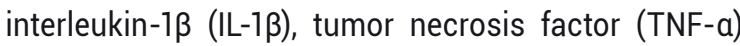
and interleukin 8 (IL-8) gene polymorphisms on the development and intensity of inflammation markers during the course of neurologic infections in patients treated in the Department of Infectious and Tropical Diseases, University Hospital in Krakow, Poland.

\section{Material and Methods}

We evaluated the results of 30 patients, 12 men and 18 women treated for BM and VM in the Department of Infectious and Tropical Diseases at the University Hospital in Krakow [mean age: 39.9 years]. The control group consisted of 30 healthy volunteers, 19 men and 11 women [mean age 44.6]. The study included 11 patients with BM and 19 patients with VM. Exclusion criteria included: other acute and chronic inflammatory states of immunosuppression and immunosuppressive therapy. In the test group, we analyzed blood morphology, the concentration of $C$ reactive protein (CRP) in the blood, and tested the cerebrospinal fluid (CSF) for the number of cells, and concentrations of glucose and protein using standard methods. Patients and control subjects were evaluated for polymorphisms of IL-1 $\beta+3953 A G$ (rs1143634), -31AG (rs 1143627), TNF-a -308AG (rs1800629) and IL-8 + 781AG (rs2227306). For this purpose, DNA was isolated from blood using a DNA Qiamp DNA Mini Kit in accordance with manufacturer recommendations (Qiagen, Germany). After quantitative and qualitative assessments, the DNA samples were normalized to a concentration of $9 \mathrm{ng} / \mathrm{ul}$. Genotyping was performed using a TaqMan SNP Genotyping Kit (Life Technologies, USA) and CFX384 Touch Real Time PCR Detection System (Bio-Rad, USA).

\section{Statistical methods}

We used nonparametric tests for statistical analysis. For comparison of the two groups, we used the Mann-Whitney test. Interdependence between select- ed parameters was determined by the Pearson correlation coefficient. Effects of polymorphisms on the level of the selected parameters were analyzed using ANOVA-Kruskal-Wallis. We also used the $\mathrm{Chi}^{2}$ test of independence. A $P$ value $<0.05$ was considered statistically significant. Calculations were performed using Statistica 10 (StatSoft@ Inc., U.S.)

The study was conducted in Accordance with the Declaration of Helsinki (1975) and approved by the Jagiellonian University Ethics Committee. All participants of the study signed an informed consent form.

\section{Results}

In the test and control groups, there was no statistically significant difference in gender $(p=0.07)$ or age $(p=0.21)$. The 19 patients with VM had an average CRP concentration of $7.40 \mathrm{mg} / \mathrm{l}(1.00-37.10 \mathrm{mg} / \mathrm{l})$ whereas in the group of 11 patients with BM the average CRP concentration was $74.02 \mathrm{mg} / \mathrm{l}$ (34.00-135.62 mg/l); the difference between the groups was statistically significant $(p=0.005)$. The WBC count $(x 10 ' 3 / \mathrm{ml})$ was 7.83 (5.43-10.00) in the VM and $16.54(6.37-22.12)$ in the $\mathrm{BM}$, with a statistically significant $(<0.001)$ difference. CSF analysis of the VM group showed 83.00 cells $/ \mathrm{ml}$ (37.00-272.00), $0.72 \mathrm{~g} / \mathrm{L}$ of protein $(0.43-0.83)$ and $2.79 \mathrm{mmol} / \mathrm{L}$ of glucose (2.49-3.20). The BM group had an average of 398 cells $/ \mathrm{ml}$ (37.00-1150.00), 1.45 $\mathrm{g} / \mathrm{L}$ of protein (1.00-2.89), and $1.51 \mathrm{mmol} / \mathrm{L}$ of glucose (1.10-2.05). Statistically significant differences were observed between the two groups in the blood glucose $(p=0.001)$ and protein $(p=0.003)$.

There was a statistically significant difference in the distribution of AA genotype of the IL-1 $\beta-31$ polymorphism $(p<0.001)$ between the test and control groups. The IL-1 $\beta$-31AA genotype was present in the healthy group but not in the test group. In addition, the GG polymorphism was more frequently observed in the test group than in the control group. In terms of the other assessed polymorphisms, IL-1 33953 , TNF- $a$ $-308, I L-8781$, there was no statistically significant difference in the distribution of these polymorphisms between the test and control groups (Table 1).

We assessed for the association between the examined gene polymorphisms and inflammatory parameters of blood and CSF. We observed a relationship between the number of WBC and the TNF-a -308 polymorphism, wherein a statistically significant difference existed between the AA and AG ( $p=0.02)$. In terms of the other assessed polymorphisms, IL-1 $\beta$ 3953, TNF-a -308, and IL-8 781, there was no statisti- 
Table 1. Genotype frequencies of IL-1 $\beta$, TNF- $\alpha$ and IL-8 genes in patients with meningitis and controls

\begin{tabular}{|c|c|c|c|c|c|}
\hline \multirow{2}{*}{ SNP } & \multicolumn{2}{|c|}{ Test group } & \multicolumn{2}{|c|}{ Control group } & \multirow{2}{*}{$\begin{array}{c}\text { Chi2 test } \\
\mathrm{p}\end{array}$} \\
\hline & $\mathrm{n}$ & GF (\%) & $\mathrm{n}$ & GF (\%) & \\
\hline \multicolumn{6}{|c|}{ IL-1 $\beta+3953$} \\
\hline GG & 20 & 66.67 & 18 & 60 & \multirow{3}{*}{$p=0.56$} \\
\hline$A G$ & 10 & 33.33 & 11 & 36.67 & \\
\hline $\mathrm{AA}$ & 0 & 0.00 & 1 & 3.33 & \\
\hline \multicolumn{6}{|c|}{ IL-1 $\beta-31$} \\
\hline GG & 18 & 60.00 & 3 & 10.00 & \multirow{3}{*}{$p<0.001$} \\
\hline$A G$ & 12 & 40.00 & 16 & 53.33 & \\
\hline$A A$ & 0 & 0.00 & 11 & 36.67 & \\
\hline \multicolumn{6}{|c|}{ TNF- $a-308$} \\
\hline GG & 19 & 63.33 & 20 & 66.67 & \multirow{3}{*}{$p=0.84$} \\
\hline$A G$ & 9 & 30.00 & 9 & 30.00 & \\
\hline $\mathrm{AA}$ & 2 & 6.67 & 1 & 3.33 & \\
\hline \multicolumn{6}{|c|}{ IL-8 +781 } \\
\hline GG & 3 & 10.00 & 7 & 23.33 & \multirow{3}{*}{$p=0.20$} \\
\hline AG & 8 & 26.67 & 7 & 23.33 & \\
\hline $\mathrm{AA}$ & 16 & 53.33 & 16 & 53.33 & \\
\hline
\end{tabular}

GF, genotype frequencies; IL-1ß, interleukin $1 \beta$; IL-8, interleukin 8; SNP, single nucleotide polymorphism, TNF- $a$, tumor necrosis factor $a$

cally significant relationship between them and WBC, CRP, TNF- $\alpha$ IL-1 $\beta$ in CSF, or inflammatory parameters of CSF: white cells, protein, and glucose.

\section{Discussion}

Our study for the first time evaluated the IL- $8+781$ polymorphism in infection, and polymorphisms of the IL-1ß: -31 and +3953 in neurological infections. A limitation of our study is that due to the small sample size, the selected gene polymorphisms of IL-1 1 , TNF- $a$ and IL-8 were analyzed together in both types of meningitis.

We have shown that the IL-1 $\beta$-31AA genotype demonstrates a statistically significant $(p<0.001)$ difference between the test and control groups. Patients in the test group did not have the IL-1 $\beta$-31AA genotype, while this genotype was present in the control group. It is possible that this genotype protects against the development of meningitis. This issue requires further research on a larger group of patients. In addition, more patients in the test group were found to have the GG genotype.

Thus far, the incidence of the IL-1 $1 \beta-31$ polymorphism in neurologic infections has not been evaluated. The effects of IL-1 $\beta$ polymorphisms have been demonstrated in sepsis. Wen et al. observed that a polymorphism at position $1470 \mathrm{GG}, \mathrm{AG}$ and 51 31GA increases the risk of severe sepsis in patients after trauma [11]. Polymorphisms at positions $-31(\mathrm{G} / \mathrm{A})$ and $-511(\mathrm{~A} / \mathrm{G})$ are also associated with more severe infections of
Plasmodium falciparum [12]. Liu et al., demonstrated a correlation between the presence of a $\mathrm{G}$ allele at position 31 , and susceptibility to infection with influenza virus AH1N1pdm09 [13]. Allele 511G, the GG genotype, and haplotype 511G/3953G can be considered one of the factors responsible for susceptibility to the development of visceral leishmaniasis, as opposed to the A allele or AA genotype at position 511 and haplotype $511 A / 3953$, which can be considered as factors promoting immunity against the disease [14]. Polymorphisms at position $3953(\mathrm{G} / \mathrm{A})$ was also observed in chronic hepatitis caused by HCV genotype 4, where the presence of the $A$ allele was associated with poorer clinical response and more severe fibrosis [15]. Sa-Ngasang et al., showed that carriers of ILI $\beta$-31G have a higher risk of developing shock during Dengue fever (Dengue Shock Syndrome), which suggests a connection with production of interleukins in the pathogenesis of the disease [16].

The most widely investigated polymorphism of the gene encoding TNF- $a$ is a polymorphism in the promoter region at position 308. Depending on the purine presence, two TNF- $a$ alleles may be present: guanine at position -308 is associated with TNF- $a 1$ and adenine at this position is associated with TNF- $a$ 2. Allele TNF- $a$ is less frequent, and it is associated with higher production of TNF-a as compared to TNF-a 1 [17]. However, the occurrence of a polymorphism at position $-863(G / A)$ is associated with a lower expression of the gene and lower levels of this cytokine [18]. Studies on 
the effects of the presence of TNF-a polymorphisms on the course neurologic infections are few. Titmarsh et al., evaluated the polymorphism of TNF- $a-308$ in groups of patients with VM, specifically invasive meningococcal disease (IMD) compared to a control group. They showed significant differences between the groups, with the genotype GG of TNF- $a-308$ polymorphism associated with a lower production of TNF-a which correlated with a higher risk of developing IMD [19]. Pujikhari et al. showed that people with -308 alleles and $-863 \mathrm{G}$ allele were more likely to develop severe Japanese encephalitis [20]. Fontes et al., in comparing the distribution of TNF-a -308 genotypes demonstrated that the TNF- $a-308$ is present more often in BM patients than in healthy people [21].

Polymorphisms in the region of -308 have been demonstrated in other acute infections, bacterial, viral, or parasitic. Thus far a correlation between the occurrence of allele TNF- 2 and more severe malaria has been shown. McGuire et al. observed that children who are homozygous for TNF- $a$ 2/2 were at seven times greater risk of developing the cerebral form of malaria or death [22]. Similarly, Cabrera et al. observed a correlation between the presence of the allele of TNF-a 2 and susceptibility to mucocutaneous leishmaniasis infection [23]. With respect to the role of TNF-a in the development of septic shock, polymorphisms of the gene coding for TNF-a have been demonstrated to have an effect on the course of sepsis. Song et al. have demonstrated the relationship between the presence of the TNF- $\alpha 2$ allele and the risk of severe sepsis, but no correlation was observed with the occurrence of this polymorphism and death [24]. Teuffel et al., came to similar conclusions in their meta-analysis [25]. Polymorphisms in the region of 308 were also demonstrated in the course of viral infections. The presence of the TNF-a 2 allele, and thus increased production of TNF- $a$, was associated with an increased risk of haemorrhagic dengue fever when re-developing the disease [26]. In the course of infection with influenza virus AH1N1pdm09 the presence of $-308 \mathrm{G}$ allele was associated with more severe disease [27].

In terms of the analyzed polymorphisms of TNF-a -308 in our study there was no statistically significant difference in the distribution between the test and control groups. The WBC count was dependent on the TNF-a-308 polymorphism, but statistical significance was only reached between AA and AG. TNF -308 polymorphisms did not affect other analyzed parameters: CRP in the peripheral blood and CSF studies: TNF- $a$, IL-1 $\beta$, cell count, protein, or glucose.
Studies on the effect of SNP IL-8 in the course of infection are few, and primarily surround infections of the gastrointestinal tract. Jiang et al. demonstrated in 2 separate studies that the AA genotype at the -251 position of the IL- 8 is a significant risk factor for primary CDI $[28,29]$. Jiang et al. further demonstrated the influence of the same polymorphism on the development of the enteroaggregative forms of Escherichia coli (EAEC) [30]. In terms of neurologic infection, Titmarsh et al., compared the prevalence of polymorphisms of IL-8 -251 in groups of patients with VM, IMD, and healthy controls. Significant difference between groups was noted; for the IL-8 -251 polymorphism, IL-8 -251AA was associated with a higher risk of VM [19]

In our study we chose the IL-8 SNP +781, which has not been analyzed in the progression of any infection. No statistically significant difference in IL-8 +781 polymorphisms were noted between the test and control groups. Polymorphisms of IL- $8+781$ had no impact on peripheral blood WBC, CRP, TNF- $a$, IL-1 $\beta$ or CSF studies, specifically: cell count, protein and glucose.

As a conclusion, we observed that the IL-1 $\beta$-31AA genotype may play a protective role in the course of neurologic infection - it was not observed in patients who presented with this disease. The WBC count in peripheral blood correlated with the TNF-a -308 polymorphism, and there was a statistically significant difference between the AA and AG subsets.

\section{Acknowledgements}

Conflict of interest statement

The authors declare no conflict of interest.

\section{Funding sources}

The study was supported by the Grant of Polish Ministry of Science and Higher Education no K/ZDS/00281, achieved by first author (GB).

\section{Abbreviations}

$\mathrm{BM}$, bacterial meningitis; $\mathrm{CRP}, \mathrm{C}$ reactive protein; $\mathrm{CSF}$, cerebrospinal fluid; EAEC, enteroaggregative forms of Escherichia coli; IL-1 $\beta$, interleukin-1 $\beta$; IL-8, interleukin 8; IMD, invasive meningococcal disease; SNPs, single nucleotide polymorphisms; TNF- $a$, tumor necrosis factor, VM, viral meningitis

\section{References}

1. Sellner J, Täuber MG, Leib SL. Pathogenesis and pathophysiology of bacterial CNS infections. Handb Clin Neurol. 2010;96:1-16

2. van de Beek D, Drake JM, Tunkel AR. Nosocomial bacterial meningitis. N Engl J Med. 2010;362:146-154.

3. Gerber J, Nau R. Mechanisms of injury in bacterial meningitis. Curr Opin Neurol. 2010;23:312-318.

4. Koedel U, Klein M, Pfister HW. New understandings on the pathophysiology of bacterial meningitis. Curr Opin Infect Dis. 2010;23:217-223. 
5. Hunt WG. Meningitis and encephalitis in adolescents. Adolesc Med State Art Rev. 2010;21:287-317.

6. Ziai WC, Lewin JJ3rd. Update in the diagnosis and management of central nervous system infections. Neurol Clin. 2008;26:427-468.

7. Brouwer MC, Tunkel AR, van de Beek D. Epidemiology, diagnosis, and antimicrobial treatment of acute bacterial meningitis. Clin Microbiol Rev. 2010;23:467-492.

8. Irani DN. Aseptic meningitis and viral myelitis. Neurol Clin. 2008;26:635-655.

9. Logan SA, MacMahon E. Viral meningitis. BMJ 2008;5:36-40.

10. Big C, Reineck LA, Aronoff DM. Viral infections of the central nervous system: a case-based review. Clin Med Res. 2009;7:142-146.

11. Wen $A Q$, Gu W, Wang J, Feng $K$, Qin L, Ying $C$ et al. Clinical relevance of IL-1beta promoter polymorphisms $(-1470,-511$, and -31$)$ in patients with major trauma. Shock. 2010;33:576-582.

12. Ouma C, Davenport GC, Awandare GA, Keller CC, Were $\mathrm{T}$, Otieno MF et al. Polymorphic variability in the IL-1beta promoter conditions susceptibility to severe malarial anemia and functional changes in IL-1beta production. I Infect Dis. 2008;198:1219-1226.

13. Liu Y, Li S, Zhang G, Nie G, Meng Z, Mao D et al. Genetic variants in IL1A and IL1B contribute to the susceptibility to. 2009 pandemic H1N1influenza A virus. BMC Immunology 2013;14:37.

14. Moravej A, Rasouli M, Kalani M, Asaei S, Kiany S, Najafipour $S$ et al. IL-1 $\beta(-511 T / C)$ gene polymorphism not IL-1 $\beta$ (+3953T/C) and LT-a (+252A/G) gene variants confers susceptibility to visceral leishmaniasis. Mol Biol Rep. 2012;39:6907-14

15. Omran $\mathrm{MH}$, Ibrahim NE, Youssef SS, Fatouh BE, Nabil W, El-Shami MM et al. Relation of interleukin-1 $\beta$ gene to treatment response in chronic patients infected with HCV genotype 4. J Infect Dev Ctries 2013;7:851-858.

16. Sa-Ngasang A, Ohashi J, Naka I, Anantapreecha S, Sawanpanyalert P, Patarapotikul J. Association of IL1B $-31 \mathrm{C} / \mathrm{T}$ and IL1RA variable number of an $86-\mathrm{bp}$ tandem repeat with dengue shock syndrome in Thailand. $J$ Infect Dis. 2014;210:138-145.

17. Wilson AG, Symons JA, McDowell TL, McDevitt HO, Duff GW. Effects of a polymorphism in the human tumor necrosis factor alpha promoter on transcriptional activation. Proc Natl Acad Sci USA 1997;94:3195-3199.

18. Fargion S, Valenti L, Dongiovanni P, Fracanzani AL. TNF alpha promoter polymorphisms. Methods Mol Med. 2004;98:47-58.

19. Titmarsh CJ, Hall S, Tzanakaki G, Kesanopoulos K, Xirogianni A, Scott RJ, et al. Comparison of cytokine gene polymorphisms among Greek patients with invasive meningococcal disease or viral meningitis. J Med Microbiol 2013;62:694-700

20. Pujhari SK, Ratho RK, Prabhakar S, Mishra B, Modi M. TNF-a promoter polymorphism: a factor contributing to the different immunological and clinical phenotypes in Japanese encephalitis. BMC Infect Dis. 2012;12:23

21. Fontes FL, de Araújo LF, Coutinho LG, Leib SL, Agnez-Lima LF. Genetic polymorphisms associated with the inflammatory response in bacterial meningitis.
BMC Med Genet. 2015; 16,70. doi: 10.1186/s12881-0150218-6.

22. McGuire W, Hill AVS, Allsopp CEM, Greenwood BM, Kwiatkowski D. Variation in the TNF-apromoter region associated with susceptibility to cerebral malaria. Nature. 1994;371:508-511.

23. Cabrera M, Shaw MA, Sharples C, Williams H, Castes M, Convit $\mathrm{J}$ et al. Polymorphism in tumor necrosis factor genes associated with mucocutaneous leishmaniasis. J Exp Med. 1995;182:1259-1264.

24. Song Z, Song $Y$, Yin J, Shen $Y$, Yao C, Sun Z et al. Genetic variation in the TNF gene is associated with susceptibility to severe sepsis, but not with mortality. PLoS One. 2012; 7, e46113.

25. Teuffel O, Ethier MC, Beyene J, Sung L. Association between tumor necrosis factor-promoter -308 A/G polymorphism and susceptibility to sepsis and sepsis mortality: A systematic review and meta-analysis. Crit Care Med. 2010;38:276-282.

26. Perez AB, Sierra B, Garcia G, Aguirre E, Babel N, Alvarez $M$ et al. Tumor necrosis factor-alpha, transforming growth factor- $\beta 1$, and interleukin-10 gene polymorphisms: implication in protection or susceptibility to dengue hemorrhagic fever. Hum Immunol. 2010;71:1135-1140.

27. Martinez-Ocaña J, Olivo-Diaz A, Salazar-Dominguez T, Reyes-Gordillo J, Tapia-Aquino C, Martínez-Hernández $\mathrm{F}$ et al. Plasma cytokine levels and cytokine gene polymorphisms in Mexican patients during the influenza pandemic A(H1N1)pdm09. J Clin Virol. 2013;58:108113.

28. Jiang ZD, DuPont HL, Garey K, Price M, Graham G, Okhuysen $\mathrm{P}$ et al. A common polymorphism in the interleukin 8 gene promoter is associated with Clostridium difficile diarrhea. Am J Gastroenterol. 2006;101:1112-1116.

29. Jiang ZD, Garey KW, Price M, Graham G, Okhuysen P, Dao-Tran $T$ et al. Association of interleukin-8 polymorphism and immunoglobulin $\mathrm{G}$ anti-toxin $\mathrm{A}$ in patients with Clostridium difficile-associated diarrhea. Clin Gastroenterol Hepatol. 2007;5:964-968.

30. Jiang ZD, Okhuysen PC, Guo DC, He R, King TM, DuPont $\mathrm{HL}$ et al. Genetic susceptibility to enteroaggregative Escherichia coli diarrhea: polymorphism in the interleukin-8 promotor region. J Infect Dis. 2003;188:506511.

Acceptance for editing: 2016-12-10 Acceptance for publication: 2016-12-22

Correspondence address: Grażyna Biesiada Department of Infectious and Tropical Diseases Jagiellonian University, Medical College 5 Śniadeckich Street, 31-501 Kraków, Poland phone: +48 124247349 email: gbiesiada@op.pl 